\title{
OS PARADIGMAS DA ENFERMAGEM OBSTÉTRICA
}

\author{
Ruth Hitomi Osava* \\ Ana Cristina d'Andretta Tanaka**
}

OSAVA, R.H.; TANAKA, A.C.D'A. Os paradigmas da enfermagem obstétrica. Rev.Ese.Enf.USP,v. 31, n.1, p. 96-108, abr. 1997.

Descreve-se a trajetória da prática de atenção ao parto na Inglaterra $e$ Estados Unidos da América, privilegiando-se as relações entre a incipiente profissão de enfermeira e a tradicional profissão de parteira, ao longo dos séculos XVIII e XIX. Propõe-se o estudo dessas relações adotando as deusas da mitologia grega como figuras arquetipicas do comportamento feminino. Relaciona a enfermeira à deusa Atenas, protetora das artes, das cidades, dos valores patriarcais, do status quo - a personificação do arquétipo da filha do pai - e a parteira tradicional à Ártemis, deusa da caça e da lua, protetora dos ermos, dos fracos e dos jovens - a personificação do arquétipo da grande irma. Sob esta perspectiva, trata do declínio da prática da parteira tradicional naqueles paises. Finalmente, equaciona a questão do paradigma da enfermagem obstetra como algo a ser constituido em consonância e cumplicidade com o movimento organizado de mulheres e suas reivindicações no campo da saúde.

UNITERMOS: Enfermagem obstétrica. Parteiras. Paradigmas profissionais. Arquétipos femininos

\section{INTRODUÇÃO}

O que tem em comum a enfermeira obstetra e a parteira? E a enfermeira obstetra e as demais enfermeiras? Como se processa a identificação profissional destes grupos, interna e externamente?

Para Kuhn ${ }^{(10)}$, o que explica a unânimidade de julgamentos profissionais de um grupo é um paradigma, ou conjunto de paradigmas. Um paradigma governa um grupo de praticantes da ciência, e qualquer estudo de pesquisas orientadas por paradigma ou que levem à destruição do mesmo, deve começar pela localização do grupo ou grupo de responsáveis que compartilham os mesmos paradigmas.

* Professor Assistente do Departamento de Enfermagem do Centro Biomédico da Universidade Federal do Espírito Santo. Doutoranda do Departamento de Saúde Materno-Infantil da Faculdade de Saúde Pública-USP.

** Professor Livre-Docente do Departamento de Saúde Materno-Infantil da Faculdade de Saúde Pablica-USP. 
O estudo de paradigmas implica em identificar uma posse comum de uma disciplina por um grupo, ou matriz disciplinar, como sugere Kuhn. A destruição de paradigmas, e sua substituição por outros, envolve um certo tipo de reconstrução dos compromissos do grupo.

Os paradigmas constituem uma espécie de negociação com outros saberes, e podem ajudar um grupo a se expandir, ou ao contrário, precipitar sua extinção. No caso das enfermeiras obstetras, é possivel afirmar que estas compartilham o mesmo paradigma profissional das demais enfermeiras, e viceversa? É possivel considerar que ambas façam parte do mesmo grupo de praticantes?

No presente trabalho pretende-se introduzir o estudo das relações entre enfermeiras e parteiras, lançando-se mão de categorias de análise não usuais na pesquisa de enfermagem, ainda que exploradas em outras áreas - no caso, as deusas da mitologia grega como figuras arquetípicas do comportamento feminino, e sua correspondência com as duas profissões.

\section{PARTEIRAS E ENFERMEIRAS NA HISTÓRIA}

\section{A CONFIGURAÇÃO DO TRABALHO DA PARTEIRA COMO UM PROBLEMA DE SAÚDE PÚBLICA}

No passado, nas raras ocasiões em que a parteira se encontrava diante de um parto complicado, em geral as anomalias de apresentação consequentes à multiparidade, ela procurava inicialmente reconhecer o que estava ocorrendo, para então sair em busca de auxílio, comumente de outra parteira mais experiente. Tão somente quando todos os recursos se esgotavam é que se deliberava pela vinda de um cirurgião, para a embriotomia ${ }^{(16)}$. Não surpreende que a presença de um cirurgião no quarto da parturiente fosse vivenciada com inquietude e ansiedade por todos os presentes.

O surgimento da enfermagem profissional, vinculada à publicidade feita em torno dos trabalhos de Florence Nightingale na Guerra da Criméia (18541856), deu uma certa respeitablidade à profissão de enfermeira no interior da classe média inglesa.

No mesmo período, a profissão de parteira começou a sofrer um declínio, inaugurado com a invenção do fórcipe obstétrico pelo cirurgião inglês Peter Chamberlen, ao final do século XVI. O que antes era percebido como "cuidar da parturiente", uma série de procedimentos ao pé-do-leito, pouco tangiveis, ganhou uma expressão concreta com o fórceps, que permitia a "visualização" da luta do homem : contra a natureza, e a substituição do paradigma não-intervencionista, pela idéia de parto como um ato controlado pelo homem. 
O fórceps teve uso restrito entre as parteiras, por razões de ordem econômica - poucas dispunham dos meios para comprar o "segredo" da família Chamberlen. Além disso, assumia-se que a mulher era intelectualmente inferior ao homem, e portanto, incapaz de dominar as novas técnicas em desenvolvimento na obstetrícia. Os paradigmas não-intervencionistas das parteiras explicam porque muitas delas rejeitavam vigorosamente as chamadas "mãos de ferro".

Nos Estados Unidos, as mulheres começam a buscar os serviços de um médico na gestação e parto em época muito recente, por volta do início do século atual. Ainda em 1910, a parteira tradicional norte-americana atendeu à cerca de $50 \%$ de todos os nascimentos ocorridos naquele país ${ }^{(17)}$.

A emergente profissão médica norte-americana, fundada em bases classistas - uma profissão masculina, branca e de classe média - deu continuidade, ao longo da metade incial do século XIX, à luta contra o que se convencionou chamar de "charlatanismo", cujas raízes assentam-se nos séculos precedentes*. Um dos alvos desta campanha foi a parteira tradicional norte-americana, circunscrita no que ficou conhecido como "midwife problem" (8) : à elas se atribuía a maior responsabilidade pelas elevadas taxas de mortalidade materna e infantil - cerca de um oitavo das crianças nascidas nos Estados Unidos no início do século, morriam nos primeiros meses de vida, boa parte entre a clientela da parteira tradicional.

Valendo-se de metáforas emprestadas da teoria dos germes, os médicos assinalavam a parteira como uma espécie de "micrococus" nociva ao "tecido social", disseminando a doença e a morte com suas unhas sujas ${ }^{(4)}$. Ao acusarem as parteiras, a corporação médica, de maneira hegemônica, transformava-se na intérprete infalível da ciência e da natureza, assim como os papas do Renascimento foram os intérpretes da bíblia e de Deus.

Exclusivamente mulheres, a maioria das parteiras dispunha de pouca base educacional e baixo poder de organização. Sua clientela, grande parte encontrada entre os mais vulneráveis, os pobres, os desnutridos, os desempregados, concentravam fatores de risco de morbidade e mortalidade que iam muito além da ação dita "nociva" da parteira.

Numerosos folhetos e livros são publicados nos Estados Unidos e Inglaterra, divulgando a crescente participação masculina no parto, ao mesmo tempo que ganham destaque nos meios de comunicação, os relatos de casos de mulheres que morreram devido a demora da parteira em chamar o médico. No mesmo período, as parteiras norte-americanas dispunham de apenas dois jornais, lidos por um segmento muito pequeno do total delas. Elas dependiam, em sua defesa, da simpatia de alguns médicos e de enfermeiras de saúde pública ${ }^{(11)}$. 


\section{ENFERMEIRAS E PARTEIRAS, OU ATENAS E ÁRTEMIS}

As relações entre a emergente profissão de enfermagem e a milenar profissão de parteira não foram amistosas. Ward "18! registra que na época, parteiras e enfermeiras inglesas se hostilizavam: as enfermeiras, vendo as parteiras com desdém, compartilhando a visão que a classe médica tinha delas 'supersticiosas, ignorantes e pouco higiênicas'. E as parteiras, vendo as enfermeiras como 'um pouco mais do que servas da profissão médica'.

Na mitologia grega, em sua versão patricêntrica, a enfermeira nightingaleana personificou principalmente o arquétipo da deusa Atenas, cujo ingresso na companhia dos deuses olímpicos foi dramática: ela saltou da cabeça do pai como mulher adulta, seu parto assemelhando-se à uma operação cesariana dolorosa. Seu pai, Zeus, engravidara Métis, a titã, e temendo um oráculo que decretara ser um menino que iria depô-lo, Zeus enganou Métis e a engoliu. Mas a criança continuou a crescer dentro dele, até que, atormentado por dor de cabeça torturante, Zeus recorreu à Hefesto, o deus da forja, que lhe abriu o crânio com um machado, dando espaço para que Atenas nascesse.

Com um grito de batalha selvagem, Atenas saltou da cabeça do pai inteiramente armada, portando seu escudo. Atenas considerava-se filha de um só genitor, Zeus, e com ele esteve associada para sempre. Enquanto arquétipo da "filha do pai", Atenas representou a mulher que tende naturalmente aos homens poderosos que têm autoridade, responsabilidade e poder, homens que se ajustam ao arquétipo do pai patriarcal ou do "homem patrão". Uma vez dado o seu voto de fidelidade, ela se torna a sua mais ardente defensora.

Bolen (1) diz que a qualidade de filha torna Atenas uma defensora dos direitos e valores patriarcais, que enfatizam a tradição e a legitimidade do poder masculino. Comumente, mantem o "status quo" e aceitam as normas estabelecidas como linhas mestras de comportamento, e são politicamente conservadoras.

De acordo com Mc Cool e col. ${ }^{(12)}$, a enfermagem prosperou em sua fase inicial porque sua configuração se afinava com os propósitos do modêlo de saúde em formação, patriarcal e centrado na figura médica. Ao mesmo tempo que se garantia o controle da prática da enfermagem, os médicos contavam com sua aliança para eliminar as curandeiras e parteiras, cujas práticas escapavam das estratégias médicas de regulação ou subjugação.

(*) Um dos mais atrozes capítulos da Inquisição, na alta Idade Média, foi a perseguiçăo às parteiras e às mulheres em geral. Em Malleus Maleficarum ${ }^{(9)}$, o manual oficial da Inquisição para a caça às bruxas, escrito em 1484 pelos inquisidores Heinrich Kramer e James Sprenger, encontra-se um texto alimentado por uma profunda misoginia, que levou à tortura e à morte mais de $100 \mathrm{mil}$ mulheres. A Inquisição teve a sabedoria de ligar a trasgressão sexual à transgressão da fé, e punir as mulheres por isso, acusando-as de pouca fé: "...tal 6 a etimologia da palavra que lhe designa o sexo, pois femina vem de fe e minus, por ser a mulher sempre mais fraca em manter e em perseverar a sua fe" ( $p$ 117). Sobre as parteiras, dizia-se que ".. Não há quem mais malefícios causem a Fé Católica do que as parteiras..."(p 156). 
Na mitologia, Atenas era protetora, conselheira, patrona e aliada de homens heróicos. Entre eles estava Perseu, que matou a górgona Medusa - o monstro fêmea que tinha serpentes como cabelos, garras de bronze e olhos arregalados, cujo olhar transformava os homens em pedra. A deusa também ajudou Jasão e os argonautas na construção do navio, e deu um freio dourado a Belerofonte, com o qual ele pôde domesticar o cavalo alado Pégaso. Durante a guerra de Tróia, Atenas foi muito ativa em defesa dos gregos.

Além de patrocinar os herois individuais e de ser a deusa olímpica mais próxima de Zeus, Atenas tomou o partido do patriarcado, no voto decisivo dado à Orestes. Este tinha matado sua mãe Clitemnestra, para vingar o assassínio de seu pai, Agamêmnon. O voto dos jurados foi empatado, quando Atenas deu seu voto decisivo à Orestes, libertando-o, e colocando os princípios patriarcais acima das ligações maternas.

As parteiras tiveram como arquétipo principal, a deusa Ártemis, conhecida como a deusa da caça e da lua. Enquanto deusa do ermos, Ártemis foi a personificação do espírito feminino independente. Irmã primogênita de Apolo, ambos frutos de uma relação extraconjugal de Zeus. Logo que nasceu, Ártemis ajudou sua mãe Leto, durante as prolongadas dores e difícil parto de Apolo. Por nove dias e nove noites, Leto sofreu dores intensas, por causa dos efeitos vingativos de Hera, a esposa legítima de Zeus.

As mulheres se dirigiam a Ártemis como auxiliar nos momentos de aflição, pedindo-lhe que pusesse fim às suas dores, ou que lhes concedesse uma morte amena, causada por suas flechas certeiras. A deusa personificou o arquétipo da "grande irmã" ; também representou as qualidades idealizadas pelo movimento feminista -empreendimento, independência dos homens e do mundo masculino, e preocupações pelos atormentados, pelas mulheres fracas e pelas jovens.

Quando Ártemis foi apresentada à Zeus, este ficou encantado com a filha, e providenciou-lhe todos os desejos. Ártemis pediu um arco e flechas, uma quadrilha de cães para com eles caçar, ninfas para acompanhá-la, uma túnica suficientemente curta para com ela correr, montanhas e selvas como seus lugares especiais e a castidade eterna. Zeus lhe concedeu tudo isso, e ainda o privilégio de fazer suas proprias escolhas.

Enquanto Atenas simbolizou a cidade, as artes e a tecnologia, Ártemis simbolizou a natureza e os ermos. A enfermeira nightingaleana personificou a disciplina, a administração, a estratégia, a racionalidade; a parteira tradicional, a independência, a relação fraternal com as mulheres, a inacessibilidade e um certo desprezo pelo que vem da urbe - no plano concreto, este desprezo pode ser representado pela resistência às inovações tecnológicas no campo da obstetrícia.

As atividades racionais, logicas, cujos exemplos paradigmáticos, as normativas de uma comissão de infecção hospitalar, ou as de tecnologia de ponta da medicina fetal, vinculam-se ao arquétipo de Atenas, e não despertam o 
entusiasmo de Ártemis, enquanto a insistência no ecologico parto natural, preferencialmente domiciliar - que causaria escândalo à Atenas - inclui-se entre os ideais profissionais da deusa da caça.

\section{O DECLÍNIO DA PARTEIRA TRADICIONAL}

Ainda no século XIX, as maternidades não eram um lugar seguro para a mulher dar à luz: em 1878, estimou-se que a mulher inglesa aumentava em seis vezes as suas chances de morrer, ao dar entrada nas maternidades daquele país ${ }^{(19)}$.

A parteira tradicional era uma boa opção para os pobres, pois além de econômicamente acessível, ela se envolvia com as tarefas domésticas, substituindo ou auxiliando a mulher por um mês ou mais após o parto.

A inegável necessidade social do trabalho da parteira tradicional dificultava sua imediata exclusão da assistência ao parto; os jovens médicos provinciais que disputavam sua clientela, não aceitariam trabalhar nas mesmas bases de remuneração. Diversas proposições são ensaiadas ao longo do século XIX, para subjugar o trabalho das parteiras ao domínio da medicina oficial.

Uma delas sugeria a concentração compulsória de mulheres médicas na obstetrícia, com o intuito de substituir a parteira, mas foi logo descartada porque o número de mulheres médicas na Inglaterra e País de Gales não passava de uma centena em 1891, e nem todas desejavam seguir a carreira obstétrica ${ }^{199}$.

Outra proposição foi a fundação de cursos para a formação de enfermeiras parteiras. A criação dessa classe de enfermeiras atendia, de acordo com Ward ${ }^{(19)}$, aos interesses do clínico geral, que pretendia dispor de um profissional que atuasse como uma espécie de satélite seu por cerca de um mês antes do parto, prestando, sob suas ordens, cuidados à gestante. A idéia não floresceu, mesmo porque não constitúa um consenso, dentro da classe médica, a necessidade de tal profissional.

Curiosamente, um dos principais defensores do trabalho da parteira foi a classe dos médicos clínicos. Para os clínicos, a participação masculina no parto constituía um atentado ao pudor, e defendiam, como saída, o treinamento das parteiras, e não a sua exclusão da assistência.

Litoff ${ }^{(1)}$ registra que em Boston, EUA, o médico clínico Samuel Gregory pessoalmente tomou iniciativa nesse sentido, criando um curso de treinamento para parteiras, a partir de 1848. A oposição da corporação médica foi grande, a tal ponto que, após treinar seis grupos de parteiras, o clínico sucumbiu às pressões dos cirurgiões.

Clínicos e cirurgiões não compartilhavam as mesmas opiniões. Para os cirurgiões, era imprescindível a presença de um médico na gravidez e parto, pelo perigo potencial que existia nesses periodos. 
Um persistente lobby junto ao Parlamento fez com que, na Inglaterra, a prática da parteira fosse regulamentada em 1902, com o projeto denominado "Midwives'Act", que tornou obrigatória a presença de um médico em todos os partos considerados anômalos, ficando à cargo do Estado o pagamento dos honorários médicos, quando a família comprovasse ser pobre ${ }^{(18,19)}$. Inicia-se, de forma crescente e definitiva, a passagem da prática da parteira para o controle estatal e para os domínios da medicina oficial.

Durante a I Grande Guerra verificou-se o primeiro envolvimento direto do governo norte-americano na política de assistência à mulher e à criança, consequência de estatísticas militares demonstrando que cerca de um terço dos homens recrutados encontrava-se fisicamente incapacitado, inclusive por sequelas de parto ${ }^{(17)}$.

A enfermeira passou a ser treinada em obstetrícia e engajar-se na luta pela elevação da qualidade da assistência materno-infantil, atuando principalmente nos redutos da parteira tradicional, prestando cuidados diretos e difundindo os padrões e conceitos da medicina oficial.

O declínio da parteira tradicional norte-americana tornou-se irreversível com a restrição governamental à entrada de imigrantes, a partir de 1920 . O parto hospitalar começa a substituir o parto domiciliar nesse mesmo período em 1900, apenas $5 \%$ das americanas deram à luz em hospitais, saltando para $25 \%$, em 1930. A mudança criou as condições necessárias para a inclusão de rotinas cirúrgicas em obstetrícia, como a episiotomia e o fórcipe profilático ${ }^{(j)}$.

De experiência profundamente subjetiva, o parto é transformado em momento privilegiado para o treinamento de médicos. A singularidade não é mais o que confere significado ao parto, e sim o que the retira o sentido. O corpo feminino passa a ser interpretado como uma máquina, e a regularidade impõe-se como a premissa básica da obstetrícia técnica e científica.

Por volta de 1930 , apenas $15 \%$ dos nascimentos ocorridos nos Estados Unidos foram assistidos por não-médicos. Em 1973, essa taxa caiu para menos de $1 \%$, de acordo com Litoff. No momento, nota-se uma tendência ascendente $-3,4 \%$ de todos os nascimentos ocorridos em $1988^{(2,3)}$. e predominantemente entre as tradicionais clientes dos parteiros não-médicos: as mulheres socialmente excluídas.

\section{A FORMAÇÃO DA PARTEIRA NO BRASIL: QUEM A FORMA, E PARA O QUÊ?}

No Brasil o ensino formal da parteira tem início em 1832, no espaço das escolas médicas, que passam a conceder o título de "parteira". Anteriormente, as aspirantes ao ofício de partejar não dispunham de uma via formal de aprendizado. A fiscalização do exercício das parteiras era extremamente frouxo, e a obtenção da licença para partejar dependia pouco de suas habilidades técnicas, 
uma vez que a única obrigação impreterível era o pagamento das taxas, pela candidata ${ }^{(6)}$.

A partir de 1931, o título de parteira é modificado para o de "enfermeira obstétrica", aproveitando a criação, em 1923, da profissão de enfermeira no Brasil. A concessão do título de "enfermeira" por escolas médicas provocou uma celeuma entre enfermeiras e parteiras, as primeiras reinvidicando que o curso de enfermagem fosse colocado como pré-requisito para o curso de parto, em discordância com as parteiras, que defendiam que a enfermagem e a obstetrícia eram profissões afins, porém distintas, e que o curso de partos deveria permanecer sob a tutela médica. A denominação "obstetriz" também serviu para designar as egressas das escolas de obstetrícia vinculadas às escolas médicas, usada em lugar de "parteira".

Com a Reforma Universitária de 1968 que, entre outras coisas, vetava a duplicação de cursos com finalidades semelhantes, foi dado o golpe de misericórdia nos cursos de partos oferecidos pelas escolas médicas, ficando à cargo exclusivamente das escolas de enfermagem, a formação de parteiras (ou obstetrizes).

A duplicidade de profissões - parteira (obstetriz) e enfermeira obstetra significava, em sua essência, dois modêlos de formação profissional: o modêlo europeu, ligado às escolas médicas, e o modêlo norte-americano, ligado às escolas de enfermagem. A mudança de tutela destruiu um paradigma profissional, de autonomia e de formação voltada exclusivamente para prática de atenção ao parto.

A respeito, Spink ${ }^{(15)}$ assinalou que, "no caso das obstetrizes, a redefinição de seus limites respondeu à inieresses hegemônicos da medicina, que transformaram uma profissão autônoma em especialidade de enfermagem, ou seja, em 'auxiliadoras do médico'..."

Considerando os atuais padrões de comportamento de enfermeiras e enfermeiras obstetras, cada um dos grupos carrega a marca indelével de suas origens, como um congênito vício (ou virtude). Um dos traços característicos da profissão de enfermeira é o apego d̀ padronização das técnicas, à sistematização e à ordem, que deixam pouco espaço para a criatividade, para a discordância e para a inovação.

Kimbro $^{(7)}$, nos Estados Unidos, analisando as atitudes de enfermeiras e enfermeiras obstetras, destaca que as primeiras usualmente envolvem-se em tarefas administrativas que vão surgindo na enfermaria durante seu plantão, dando grande importância à manutenção do status quo, à manutenção da rotina e o apego à filosofia do 'não é desse modo que é feito aqui'.

Enfermeiras obstetras, por seu lado, requerem coisas que não fazem parte da rotina. Uma vez que são também enfermeiras, elas tem idéias sobre o que a enfermeira do setor deveria fazer, e podem ser extremamente críticas ao trabalho dela ou à sua omissão. Como trabalham com maior margem de liberdade, são percebidas e percebem-se fazendo coisas mais interessantes que a enfermeira. 
No clássico estudo sobre o funcionamento das organizações como sistemas sociais de defesa contra a ansiedade, Menzies ${ }^{(13)}$ assinala que a obsessão pela sistematização faz "(...) uma enfermeira tornar-se uma espécie de aglomerado de técnicas de enfermagem, sem individualidade; cada uma é, portanto, perfeitamente intercambiável com outra do mesmo nivel de competência." $\mathrm{O}$ preço a se pagar é a supressão da função vivificante do trabalho humano.

A obsessão pelo controle, pela previsão, leva à sistemática exclusão da dimensão subjetiva da experiência, foco de resistência à clonagem, e o que garante a originalidade e singularidade do trabalho humano. No momento em que importa menos explicar os fatos, mas determinar a perspectiva de onde devem ser vistos e ditos, instaura-se uma crescente desvitalização da experiência humana.

No caso das parteiras, foi a própria força de Ártemis - sua independência do mundo masculino e de seus valores-que precipitou a sua queda. Mais vulnerável que Atenas, Artemis vestia apenas uma túnica curta, enquanto Atenas chegou ao cenário olímpico com esplêndida couraça dourada.

Bolen ${ }^{(1)}$ considera que, no mundo competitivo, o arquétipo de Atenas tem indiscutível vantagem sobre o de Ártemis. A mulher tipo Ártemis tem objetivos e compete, mas não e "encouraçada" como a deusa Atenas, e pode ser pessoalmente atingida por hostilidades, tornando-se emotiva e menos efetiva. $\mathrm{Na}$ mesma situação, Atenas avalia friamente o que está acontecendo, antes de se colocar em ação.

Pragmática, Atenas não consegue compreender por que Ártemis sente-se pesarosa ao ser excluída da experiência vivificante do parto*. Atenas assume sem pesar e sem constangimento que outras áreas se abriram para a enfermagem obstétrica, - ainda que atendendo mais aos interesses da corporação médica que aos dela - e que fazer partos não é fundamental para a construção de sua identidade profissional.

Atenas tem habilidade para intimidar os outros com suas premissas logicas, e afastar a espontaneidade, a vitalidade e a criatividade das pessoas que não são como ela. Este é o seu "efeito medusa", o monstro com serpentes ao invés de cabelos, cuja aparência terrível transformava em pedra qualquer coisa que olhasse para ela. Metaforicamente, representa o poder de desvitalizar a experiência dos outros, de rebaixar a experiência subjetiva de outra pessoa, mesmo inconscientemente, pela sua necessidade de equacionar tudo em têrmos racionais. No plano social, esse efeito pode apenas entediar ou enfurecer, mas quando Atenas se encontra numa posição de autoridade e julgamento, serve para amedrontar e petrificar.

A parteira, outrora designada carinhosamente de "comadre", manteve uma relação fraternal com outras mulheres, à semelhança da deusa Ártemis - a deusa se cercava da companhia das ninfas - mantendo relacionamentos mentores com mulheres mais jovens. Mesmo na velhice, suas atividades não costumam cessar: estará ocupada atendendo gratuitamente à gestantes adolescentes, por 
exemplo, ao contrário de uma desvitalizada Atenas, que provalvemente optará por funcionar longe da enfemagem.

Como dificuldades psicológicas de Ártemis, estão a sua inacessibilidade, sua incapacidade de ouvir o que os outros dizem, a crueldade no julgamento das ações alheias, colocadas em têrmos de absoluto preto-no-branco, e sua raiva destrutiva. Esta raiva só é ultrapassada pela de Hera, esposa legítima de Zeus, que se enfurece "com a outra mulher", enquanto Ártemis se enfurece "com o homem" (ou valores masculinos).

As qualidades de estrategista permitiram a mulher Atenas sobreviver num mundo masculino. A diplomacia é um domínio no qual Atenas se sai bem; ela é reconhecida por usar a sua inteligência e alianças para explorar o mundo dos homens. Mas recebe críticas de mulheres do tipo Ártemis - as feministas reagem com raiva às bem sucedidas carreiras das mulheres do tipo Atenas. Elas acusam-nas de defender as posições patriarcais, e ao mesmo tempo, usufruir dos benefícios obtidos através das lutas dos movimentos femininos.

Tais mulheres não ajudam suas "irmãs" a progredir, e na verdade, podem tornar o progresso mais difícil. Sabe-se que a enfermagem tem sido uma das últimas profissões a ser afetada e a solidarizar-se com o movimento feminista.

No mito, certa vez Atenas teve uma amiga que era como irmã, chamada Palas. Durante um jogo competitivo, Atenas fere acidentalmente a amiga, matando-a (daí a origem do nome Palas Atenas, homenagem à amiga). Na vida real, a companheira tipo Atenas se esquece da importância de seus relacionamentos e se concentra exclusivamente em vencer, "matando" a amizade.

A mulher tipo Atenas zanga-se com a mulher que se queixa, mais do que com o homem contra a qual é feita a queixa. Como deusa, ela fica enraivecida porque a mulher torna pública uma ação que submete o homem - entenda-se, as instituições patriarcais - à crítica.

Atenas nunca foi criança; nasceu já como adulta, e esta metáfora aproxima-se da experiência da mulher tipo Atenas. Bolen (1) aponta a busca dessa criança como um dos caminhos para o crescimento psicológico de Atenas, e ensina que "para recuperar a criança, a mulher tipo Atenas deve parar de abordar novas experiências como o faria um 'adulto sensato', modo que ela usa desde criança. Ao contrário, precisa abordar a vida como se ela fosse uma criança estarrecida e tudo fosse novo e ainda por ser descoberto. Quando uma criança está fascinada por alguma coisa nova, ela capta tudo. Ao contrário de Atenas, ela não tem noção preconcebida do que isso seria, não é cética, e não põe rótulos velhos e familiares na experiência e depois a arquiva". 


\section{CONCLUSÃo}

A interpretação das relações entre a emergente profissão de enfermeira e a milenar profissão de parteira tradicional , o significado de suas alianças, de suas rivalidades e de suas afinidades, pelo artifício da aproximação com as deusas da mitologia grega, é uma tentativa de ampliar nossa percepção a respeito de nossos próprios paradigmas profissionais.

Os mitos são extremamente simples em sua formulação, e entretanto, tem uma enorme capacidade explicativa, difícil de ser lograda por outras formas de argumentação. $\mathrm{Na}$ psicologia acadêmica, com 'seu apego pelas abstrações masculinas - a linguagem racional e espiritualmente insensibilizante - as palavras não provocam lampejos de reconhecimento, nem excitam os sentidos, como o fazem as narrativas épicas.

No atual modêlo de organização da assistência ao parto, o momento do trabalho de parto tem sido sistematicamente suprimido ou ignorado como um momento privilegiado para o crescimento psicológico da mulher. Ao médico, repugna-lhe as secreções e os odores femininos no parto, perturba-o os gritos da mulher, e aterroriza-o os "caprichos da natureza". O paradigma médico de atenção ao parto é estritamente intervencionista, cirúrgico - a obstetrícia científica nasceu sob a tutela cirúgica - e fundado no arquétipo do herói.

Com a exclusão da parteira da prática de acompanhamento do trabalho de parto, tenha ela a designação que tiver, parteira, obstetriz, enfermeira obstetra - não creio que isso seja o mais relevante - permaneceu um "nicho" que até o momento não foi ocupado por nenhuma outra categoria.

Não é fortuito que nesta era antinstintiva, seja o trabalho do médico o modelador do trabalho de parto, e não o contrário, e que a operação cesariana desfrute de enorme prestígio entre os profissionais da saúde - fortemente estruturado em torno da idéia de segurança, enquanto o parto normal configurase cada vez mais como um sofrimento desnecessário ${ }^{(14)}$.

Uma das pautas do movimento organizado de mulheres é a revisão crítica dos modos de assistência ao parto, e uma preocupação com a segurança, com o direito de escolha e com a qualidade da experiência de dar à luz, para a mulher e para o casal. Infelizmente, tais metas não tem provocado um consistente engajamento por parte das enfermeiras obstetras, ainda que possam ser elas, no plano do crescimento profissional, uma das principais beneficiárias destas mudanças, desde que se assumam e sejam percebidas como um elemento valioso e imprescindível na promoção da segurança e da qualidade da experiência singular de dar à luz, no contexto hospitalar e extra-hospitalar.

$O$ paradigma da enfermagem obstétrica encontra-se naquilo à que seus praticantes prestam adesão. A valorização do tecnológico em sua prática, ou a busca de recursos alternativos, a recusa ao que é dado como rotineiro, ou sua reafirmação, são evidências que nos ajudam a compor o estado atual dos paradigmas da enfermagem obstétrica. 
Um paradigma é um conjunto de regras e regulamentos que, em primeiro lugar, estabelecem limites, e em segundo lugar, nos dizem como devemos agir. Pelos paradigmas, selecionamos as informações que nos interessam, e selecionar significa, simultâneamente, escolher e excluir.

Uma mudança de paradigma acontece quando os modos de resolver uma questão não mais conseguem oferecer soluções eficazes aos nossos problemas. Dito de outro modo, sentimos necessidade de mudar nossos paradigmas quando ocorre uma mudança drástica em nossa percepção.

A destruição de velhos paradigmas, e sua substituição por outros, implica na reconstrução de nossos compromissos em torno de algumas premissas comuns. Saber o valor que atribuímos ao humano e ao tecnológico, o peso do intuitivo e do racional em nossas decisões, o sentido de nossas parcerias, o sentido da escolha por um tipo de clientela e por um modêlo de assistência, é reconhecer os paradigmas que nos orientam. A clareza a respeito do que selecionamos e do que excluímos nessas escolhas, ajuda-nos a compreender que tipo de solução estamos dando à nossa história enquanto profissão.

\section{REFERÊNCIAS BIBLIOGRÁFICAS}

01. BOLEN, J.S. As deusas e a mulher; nova psicologia das mulheres. São Paulo, Paulinas, 1990.

02. DECLERQ, E.R. The transformation of American midwifery: 1975 to 1988. Am.J.Publ.Health, v.82, n.5, p. 680-4, 1992.

03. W__ Where babies are born and who attends their birth: findings from the revised 1989. United States Standart Certificate of Live Birth. Obstet.Gynecol., v.81, n.6, p.997-1004, 1993.

04. ENHENREICH, B.; ENGLISH, D. For her own good: 150 years of the expert's advice to women. London, Pluto Press, 1979. p.69-97: Science and the ascent of the experts.

05. GRAHAM, S.B.; CATANZARITE, V.; BERNSTEIN, J.; VALERA-GITTINGS. A comparison to attitudes and practices of episiotomy among obstetrical practitioners in New México. Soc.Sci.Med., v.31, n.2, p. 191-201, 1990.

06. JORGE, D.R. Evolução da legislação federal do ensino e do exercício profissional da obstetriz (parteira) no Brasil. Rio de Janeiro, 1975. 213p. Tese(Livre-Docência) Escola de Enfermagem, Universidade Federal do Rio de Janeiro.

07. KIMBRO, C.D. The relationship between nurses and nurse-midwives. J.Nurse Midwife, v. 22, n. 4, p. $28-31,1978$.

08. KORBIN, F. The American midwife controversy: a crisis of professionalization. Bull.Hist.Med., v.40, p.350-63, 1966.

09. KRAMER, H.; SPRENGER, J. O martelo das feiticeiras. (Malleus Maleficarum). Trad. de FROES, P. 8.ed. Rio de Janeiro, Rosa dos Tempos, 1991. 
10. KUHN, T.S. A estrutura das revolucōes científicas. 3.ed. São Paulo, Perspectiva, 1994.

11. LITOFF, J.B. The midwife throughout history. J.Nurse Midwife, v.27, n.6, p.3-11, 1982.

12. Mc COOL, W.F.; Mc COOL, S.J. Feminism and nurse-midwifery, historical overview and current issues. J.Nurse Midwife, v.34, n.6, p.323-34, 1989.

13. MENZIES, I. O funcionamento das organizaçסes como sistemas sociais de defesa contra a ansiedade. Trad. RODRIGUES, A.M. Sao Paulo, Escola de Administração de Empresas de São Paulo da Fundação Getálio Vargas, 1970 /mimeografado/

14. OSAVA, R.H.; MAMEDE, M.V. A assistencia ao parto ontem e hoje: a representaçáo social do parto. J.Bras Ginecol., v. 105, n.12, p.3-9, 1995.

15. SPINK, M.J.P. A regulamentação das profissðes de saúde: o espaço de cada um. Cadernos FUNDAP, v.5, n.10, p.24-43, 1985.

16. TAYLOR, R.W. Difficult labor: yesterday and today. Midwives Chron, v.83, p.142-7, 1970.

17. TOM, S.A. The evolution of nurse-midwifery: 1900-1960. J.Nurse Midwife, v.27, n.4, p.413,1982 .

18. WARD, A.R. The passing of the midwives'act, 1902. Part I, Midwives Chron., v.94, n.1121, p.190-4, 1981.

19. The passing of the midwives'act, 1902. Part II. Midwives Chron., v.94, n.1121, p.237-42, 1981

OSAVA, R.H.; TANAKA, A.C.D'A. The nurse-midwifery paradigms. Rev.Esc.Enf.USP,v. 31, n.1, p. 96-108, apr. 1997.

The course of childbirth care practice in England and in the United States of America can be described by focusing on the relationship between the incipient nursing profession and the traditional profession of midwife, throughout the XVIIIth and the XIXth centuries. This paper proposes the study of such a relationship by adopting the Greek mythology goddesses as archetypical figures of female behavior. It relates the nurse to the goddess Athena, protector of the arts, the cities, the patriarcal values, the status quo - the personification of the father's daughter archetype - and the traditional midwife to Artemis, goddess of the hunt and the moon, protector of the wilderness, the weak, and the young - the personification of the great sister archetype. Under such a perspective, it deals with the decline of the traditional midwife practice in those countries. Finally, it poses the question of the obstetrics nursing pattern as something to be constituted in conformity and in cumplicity with the women's organized movement and their claims in the field of health.

UNITERMS: Nurse-midwifery. Traditional midwife. Professional paradigms. Female archetypes. 